1. REKTORALE INHULDIGINGSREDE: DIE PU VIR CHO: VERANKERD IN SY BEGINSELS EN GERIG OP DIE TOEKOMS *

\title{
C.J. REINECKE
}

Rektor, Potchefstroomse Universiteit vir Christelike Hoër Onderwys, Potchefstroom, 2520.

\section{AANHEF}

Meneer die Kanselier

Ons staan op die vooraand van die laaste dekade van die twintigste eeu. In wye verband is die huidige oordeel dat hierdie dekade beslissend kan wees vir die sinvolle voortbestaan van ons land en al sy mense. As sentra van kennis en geleerdheid en as belangrike bron vir die verskaffing van leiers vir die volgende generasies, is universiteite in 'n sleutelposisie wat hierdie kritieke fase in die geskiedenis van ons land betref. Soos in die verlede sal die PU vir $\mathrm{CHO}$ as 'n Christelike universiteit ook in die toekoms op ' $n$ eie en unieke wyse sy rol vervul. Ek vra daarom $u$ aandag vir die onderwerp.

PU vir CHO: VERANKERD IN SY BEGINSELS EN GERIG OP DIE TOEKOMS

In die behandeling van hierdie onderwerp word drie hoofsake toegelig.

1. Die universiteitswese in die branding.

* Rede gelewer deur prof. C.J. Reinecke op 10 Februarie 1989 te Potchefstroom tydens sy inhuldiging as Rektor van die PU vir CHO.

* Die rede word in Koers gepubliseer in voortsetting van 'n lang tradisie van publikasie van rektorale intreeredes. 
2. Drie kernuitdagings vir die toekoms.

3. Die deelname van die $\mathrm{PU}$ vir $\mathrm{CHO}$ as antwoordgewend op die genoemde vitdagings.

\section{UNIVERSITEITSWESE IN DIE BRANDING}

Kragtens sy wese en funksie bestaan 'n universiteit in 'n voortdurende wisselwerking met in verskeidenheid ander instellings asook met die breër maatskaplike orde waarbinne dit funksioneer: $n$ omgewing wat voortdurend aansprake en eise op ' $n$ universiteit makk. Universiteite wereldwyd beleef in die huidige dekade ' $n$ tydperk waar daar van buite die universiteite skerp en kritiese vrae oor die plek, rol en bestaansreg van individuele universiteite asook oor die universiteitswese gevra word. In 'n verslag van 'n internasionale konferensie van die Organization for Economic Cooperation and Development word hierdie tendens soos volg kernagtig saamgevat:

"... the crisis in higher education is not merely one of public confidence vis-a-vis the performance of higher education; it is also, and perhaps more fundamentally, an internal crisis of purpose, that is one which touches on the very nature of individual institutions, their roles and functions and their place in the total higher education system. In this, a reappraisal of the special position of the university appeared as crucial".

In hierdie verband het die Komitee vir Universiteitshoofde (KUH) in 1987 op eie inisiatief ' $n$ omvattende ondersoek geïnisieer wat gelei het tot die verslag getitel "Makro-aspekte van die universiteitswese binne tersière verband in die RSA". Hierdie verslag is in Januarie 1988 by die vergadering van die KUH ter tafel gelè. In die verslag word die effek van omgewingsinvloede op die doeltreffende funksionering en wenslike ontwikkeling van die universiteitswese in die RSA behandel en die volgende gevolgtrekking gemaak:

"In die lig van die beperkte finansiering, die Eerste-Derdewéreldsituasie, die bestaande realiteite in universiteite en toenemende verpligtings, is 'n herstrukturering van universiteite aangewese ... Rasionalisasie in die tersière onderwyssektor en universiteitswese behoort doelgerig beplan 
en geïmplementeer te word. Rasionalisasie op hierdie vlak beteken die aanpassing of verandering van die missies van die instellings, die uitskakeling van instellings of die stigting van nuwe instellings ten einde die behoeftes van die toekoms te ondervang. Voorts impliseer dit nouer samewerking tussen unversiteite en tegnikons. Indien inrigtings binne tersière onderwysverband nie gesamentlik die aksie kan onderneem nie, sal die staat op hierdie vlak van rasionalisasie die inisiatief moet neem."

Hierdie enkele aanhaling is voldoende on te illustreer dat in die genoemde verslag binne die Suid-Afrikaanse konteks, ook deurgedring is tot vrae oor die rol, funksie en wese van die universiteit as instelling. Gesien die verreikendheid van sommige aanbevelings asook die diversiteit in die missie van die huidige universiteite in Suid-Afrika, is dit enigsins begryplik dat die KUH die verslag slegs as ' $n$ werksdokument en nie in sy geheel as standpunt van die KUH aanvaar het nie. Uit hierdie scenario van die internasionale en nasionale beeld van die huidige universiteitswese kan die volgende drie oorhoofse standpunte gestel word:

- Individuele universiteite, asook die universiteitswese het weens eksterne faktore duidelik in 'n branding beland. So ' $n$ krisis is vir die universiteit egter nie iets nuuts nie, maar pas inderdaad by die wese van 'n instelling wat in 'n leidinggewende posisie verkeer. Die krisis is 'n noodsaaklike element om te verseker dat die universiteit op die voórpunt van die tye kan beweeg - inderdaad in die brandpunt kan staan van die uitdagings van elke nuwe tydvak. Hieroor het prof. H.G. Stoker reeds in die eerste dekade van die bestaan van ons universiteit as selfstandige inrigting geskryf:

"Elke tydsgewrig het 'n universiteit wat by hom pas. Met die verandering van die tye verander ook die taak van die universiteit. Waar ' $n$ verandering in die tye fundamenteel is en nie geleidelik geskied nie, spreek ons van 'n krisis. Dergelike wendinge in die hele geskiedenis plaas ook die universiteit voor krisisse. Met in krisis kom die universiteit voor die vraag te staan of dit aan die eise van die tyd beantwoord." 
Die feit dat die universiteite op 'n daadwerklike wyse die huidige situasie intern en ekstern as 'n krisis beleef en daarop reageer, is tekenend daarvan dat hulle nog op die voorpunt wil bly beweeg - ook as sentra wat as kragbron denkend wil leiding gee in die besondere tydvak waarin en waarvoor ons staan. Wat die PU vir CHO betref, is dit noodsaaklik dat die aard van die besondere kragte wat in hierdie tyd werksaam is, prinsipieel deurgrond moet word sodat die $\mathrm{PU}$ vir $\mathrm{CHO}$ as Christelike Universiteit antwoordgewend op hierdie eise van ons tydsgewrig kan reageer.

- Die feit dat die KUH die verslag van hulle ondersock nie eenstemming as standpunt kon aanvaar nie, is vry algemeen as simbool van in innerlike onmag en swakheid van die KUH vertolk. Inderdaad is dit jammer dat die verslag as geheel nie vir die Komitee aanvaarbaar was nie. Hierdie gebeure getuig egter ook dat die Suid-Afrikaanse universitère sisteem nog oor die inherente gesonde karaktereienskap van verskeidenheid beskik, wat een van die wesenseienskappe van 'n lewenskragtige universitère sisteem is. $J$ uis in in land met die heterogeniteit soos dié in Suid-Afrika is verskeidenheid binne 'n universitère sisteem 'n noodsaaklike element vir die kritiese gesprek warsonder die denke nie geslyp, verskerp en verdiep kan word nie. Kleurlose kompromisme was nog nooit deel van in lewenskragtige universitère sisteem nie - iets waarvan die huidige universiteite in Suid-Afrika gelukkig ook nog nie die slagoffer is nie.

- Om egter sy rol en funksie in 'n nuwe era te vervul, sal elke universiteit 'n indringende selfondersoek oor sy eie unieke missie moet doen, maar ook uitwaarts die eise van die tyd nou en vorentoe grondig moet evalueer. Aan laasgenoemde wil ek vervolgens aandag gee.

\section{HUIDIGE EN TOEKOMSTIGE OMGEWINGSTENDENSE}

\subsection{Inleiding}

In die afgelope aantal jare is 'n groot aantal gespesialiseerde konferensies en simposia aan huidige en toekomstige omgewingstendense in Suid-Afrika gewy. Daarom word hier nie van nuuts af ' $n$ wetenskaplike analise en uiteensetting daarvan gegee nie. Drie sake wat die toekomstige rol van dic Suid-Afrikaanse 
universiteite en in die besonder die PU vir CHO direk raak, kom egter veral na vore en sal breër toegelig word.

\subsection{Belegging in mensemateriaal}

Allerweë word die mense waroor $n$ land beskik, beskou as een van sy grootste bates. Soos met ander bates kan ook die mensemateriaal van ' $n$ land nie tot sy reg kom tensy dit ontgin word nie. Die prosesse van onderwys, opleiding en ontwikkeling is die meganismes waardeur dit bereik kan word. In sy boek getitel Human Resources and the Wealth of Nations skryf F.H. Harbison:

"... human resources - not capital, nor income, nor material resources - constitute the ultimate basis for the wealth of nations ... Clearly, a country which is unable to develop the skills and knowledge of its people and to utilize them effectively in the national economy will be unable to develop anything else".

Dit is uit hierdie aanhaling duidelik dat mannekragontwikkeling die ontwikkeling van $n$ land, sy hulpbronne en sy mense ten grondsiag lé. Veral twee aspekte is vir die universiteite van belang, naamlik die mannekragaanbod en die behoeftes van die arbeidsmark. Die ondersoek van die $\mathrm{KUH}$ asook ander onafhanklike ondersoeke lei almal tot dieselfde beeld en gevolgtrekking:

- Die aantal blanke leerders wat vir na-skoolse opleiding in die toekoms sal kwalifiseer, sal globaal gesproke konstant bly, terwyl die aanvraag vir na-skoolse opleiding vanuit die ander bevolkingsgroepe en veral vanuit die swart volkere geweldig sal toeneem - moontlik tot 'n verhouding van so hoog as 20:1 vir elke blanke kind teen die jaar 2000.

- Die opvoedkundige peil van die werkerskorps in Suid-Afrika vertoon hiernaas die onrusbarende beeld dat in 1980 ongeveer $24^{\circ}$ van die ekonomies bedrywige deel van die totale bevolking géen opvoedkundige kwalifikasie gehad het nie en dat slegs $7 q$ van hierdie bevolking oor 'n na-skoolse kwalifikasie beskik het. Net 28 van die totaal het oor 'n universiteitskwalifikasie beskik. 
Elke universiteit afsonderlik, maar ook die universiteite gesamentlik, sal indringend moet besin oor die wyse warop universiteite hulle sleutelrol in die mannekragontwikkeling van die land sal moet nakom. Indien dit nie realiseer nie kan hierdie grootste bate van die land, naamlik sy mense, tot die grootste katastrofe vir die land ontaard. In noue aansluiting hierby behoort 'n tweede belangrike omgewingsfaktor vir die universiteite, naamlik die van wetenskap en tegnologie aandag te kry.

\subsection{Wetenskap en tegnologie}

Wetenskap en tegniek is twee interafhanklike werklikhede. Deur die wetenskaplike navorsing en denke kom nuwe kennis en insig tot stand wat deur die tegniek tot werkbare en benutbare produkte ontsluit word. Internasionale studies het aangetoon dat juis ' $n$ land se vlak van wetenskap en tegnologie ' $n$ hoofdryfveer in die positiewe ontwikkeling van die volkshuislouding is. Hierdie positiewe rol van die wetenskap en tegnologie is te herlei tot die invloed daarvan op produktiwiteit en werkskepping, langtermyn ekonomiese groei en internasionale mededingendheid. Die vlak van die wetenskap en tegnologie beinvloed direk die welsyn van 'n bevolking. As die land op wetenskaplike en tegnologiese gebied sou stagneer, sal dit sy internasionale posisie laat agteruitgaan en vir $n$ land soos Suid-Afrika sal dit 'n oorgang na volle derdewèreldstatus beteken. Die belangrike rol van tegnologiese ontwikkeling blyk uit die volgende aanhaling:

"Dit word gesien as die sleutel om die drie produksiefaktore, te wete mannekrag, grondstowwe en kapitaal te ontsluit en optimaal aan te wend. Dit impliseer goed opgeleide wetenskaplikes, ingenieurs, bestuurslui, tegnoloë en tegnici om die tegnologie te ontwikkel, te absorbeer en toe te pas".

Selfs vir 'n leidinggewende land soos die VSA word hierdie saak voortdurend beklemtoon, soos geillustreer deur 'n onlangse uitspraak van die White House Science Council van die VSA:

"How we, as a nation, succeed in achieving our goals in matters of health, economic strength and national security will depend critically on how effectively we deploy our science and technology". 
Die ondersoek van die KUH kom tot dieselfde konklusie ten opsigte van die belang van navorsing, wetenskap en tegnologie maar onderstreep ook die volgende:

"Dit is mede deur volgehoue selfstandige en kreatiewe ondersoek dat die kennis en insig verwerf kan word wat nodig is vir die fisiese oorlewing in 'n tegnologiese wèreld en vir die geestelike en sosiale aanpassings en morele beslissings wat nodig is om, naas fisiese oorlewir.g, ook 'n sinvolle menslike bestaan te verseker".

Daarom moet ook aan 'n derde omgewingsfaktor aandag gegee word, naamlik diè van geestelike waardes.

\subsection{Geestelike waardes}

Teenoor' die wesenlike gevaar van 'n verval na 'n derdewèreldsamelewing, staan die teëpool van 'n vertegnokratiseerde samelewing. In die Suid-Afrika van die toekoms sal komponente van beide waarskynlik beduidend en deurlopend aanwesig wees. Die besondere eis wat daarom aan die hoëvlakmannekrag van die volgende dekades gestel sal word, is nie alleen dié van wetenskaplike en tegniese geskooldheid nie, maar ook diè van denkende leierskap wat antwoordgewend op die sosiale en lewensbeskoulike vraagstukke van die land en die tyd sal kan reageer. Die invloed van wetenskap en tegniek het die denke van die moderne mens so geinfekteer dat dit tot geestelike vervlakking lei met dekadensie as 'n reële moontlike eindresultaat. In die artikel "The Moral Dilemma's of Modern Science" word hierdie standpunt skerp deur H. Skolimowski verwoord:

"Now we must clearly understand that the nature of knowledge determine the nature of the world around us. There is no understanding of the world without the intervening agent which is called knowledge. The dominant position of science in our systems of learning assures the domination and perpetuation of the scientific world through the spectacles of science. The ideal of the scientific mind which is geared to factuality, objectivity and abstractedness is one side of the coin of which the other side is moral indifference and ultimately moral anaesthesia. The immorality of science lies in the fact that it makes us forget that man is 
a moral phenomenon, that it desensitizes us as ethical agents, that it purifies man of moral concerns. Within rigorous curricula of modern scientific-rational education we are taught to be objective, not compassionate; we are taught to be efficient, not morally concerned. Our mind is prodigiously developed to seize physical relationships and connections, but is lamentably unprepared to seize and articulate human and moral relationships and connections".

Die grondoorsaak van hierdie piobleem van die verdwyning van geestelike waardes is die nivellering van God in die werklikheid. In sy intreerede, gehou op 23 Februarie 1951, het prof. J.C. van Rooy, eerste Rektor van die PU vir $\mathrm{CHO}$ as selfstandige inrigting, dit só gestel:

"Die wetenskap het in ons tyd gevorder tot op die grense van die menslike denkvermoë ... Die proses van wetenskaplike navorsing op fisiese en psigiese terreine het uitgeloop op 'n immanensie-filosofie wat denke en syn, bewussyn en werklikheid identifiseer. Gevolg hiervan is dat die bestaan en werking van God in transendente vorm agter en bo die kosmiese werklikheid finalitèr opgehef word ... Nieteenstaande die vordering in die wetenskap het daar ' $n$ verswakking in die oordeei ingetree. Kennis van allerlei aard word in groot hoeveelhede by die massas aangebring, maar verwerking daarvan in die lewe ontbreek totaal. Die onverwerkte kennis belemmer die oordeel en staan wysheid in die pad. Net verswakking van oordeel gaan gepaard 'n verswakking van die kritiese behoefte".

Daarom is dit noodsaaklik dat die leiers van die tockoms in staat moet wees om nie alleen die wetenskap en tegnologie te beheers nie, maar ook om dit krities te kan beoordeel en te deurgrond. Vir rigtinggewende denke sal insig in waardes, norme en oordeelsvermoë van ewe deurslaggewende belang wees as wetenskaplike en tegnologiese kundigheid. Dit sal juis die geestelike kwaliteit van hierdie leierskorps wees wat kernsake soos die politieke koers, sosiale en maatskaplike strukture, ekonomiese geloofwaardigheid - inderdaad die hele samehang van die intermenslike verhoudinge in die land - sal bepaal. 


\subsection{Samevattend}

Die realiteite van die bevolkingsamestelling, bevolkingsgroei en ontwikkelingspeil in die RSA, die noodsaak vir wetenskaplike en tegnologiese groei en die gevaar van vertegnokratisering en lewensbeskoulike verwildering is drie van die grootste eksterne uitdagings warteen die universiteit te staan kom om antwoordgewend vir die toekoms te reageer. Vervolgens word aandag gegee aan enkele standpunte hierteenoor, spesifiek vanuit die gesigspunt van die Christelike universiteit.

\section{DEELNAME VAN DIE PU VIR CHO}

\subsection{Voorsiening van mannekrag}

Uit projeksies vir mannekragbehoeftes en die ontwikkelingspeil van die Suid-Afrikaanse bevolking is aangetoon dat die universiteite onteenseglik ' sleutelrol vervul en sal moet bly vervul ten opsigte van die voorsiening van hoëvlakmannekrag. Kragtens sy karakter bedien elke universiteit 'n besondere snit van die gemeenskap waaruit hierdie mannekrag moet kom. Ook met die oog op die toekoms is dit belangrik om te let uit watter en vir watter snit van die gemeenskap die PU vir CHO tot stand gekom het. Die mees historiese en primère bron vir so ' $n$ evaluering is die Handelinge van die Vierde Algemene Sinodale Kerkvergadering, wat in Mei 1869 te Potchefstroom plaasgevind het. Die 38-tal afgevaardigdes was afkomstig vanaf Waterberg in die Noorde, tot die OVS en Middelburg in die Suide. Dit was duidelik nie 'n eng streeksgebonde gemeenskap nie, maar het kultureel 'n Afrikanergemeenskap, afkomstig vanaf die Kaapkolonie tot die Transvaal, verteenwoordig. Lewensbeskoulik was dit Christene van 'n Calvinisties-gereformeerde grondslag wat hulle doelwitte met die ter stigte inrigting duidelik in Artikel 77 van die Handelinge van die Sinode verwoord het:

"De Sinode besluit, dat de kweekschool te Burgersdorp zoo ingerigt worde, dat er niet alleen predikanten aangevormd worden, maar ook jongelingen zich kunnen bekwamen tot onderwijsers der jeugd, ja dat ook jongelieden, zonder een bestemd doel te hebben, gelegenheid gegeven 
wordt, naar hunne vatbaarheid gebruik van de school te maken, allen onderworpen aan de regulatien van die school".

Uiteraard was hierdie ter stigte inrigting 'n privaat instansie en as sodanig gefinansier, kon dit daarom 'n onafhanklike keuringsmodel vir die inrigting formuleer om te verseker dat die doelwitte van die inrigting verskans sou wees. Artikel 78 van die Handelinge van die Sinode bepal dan ook duidelik wie daar mag onderrig gee en daar studeer, namlik

"... dat as leeraren aan de school niet anders zullen opnemen dan personen in het bezit van attestaten van lidmaatschap der gereformeerde kerk van Zuid-Afrika of kinderen ... van lidmaten dier kerk, en die dit niet bezitten anders dan met toestemming van het college van curatoren".

Daarmee het die stigters eenvoudig maar duidelik uitgespel wat die vertrekpunte en verwagtings vir die nuwe inrigting is. $U$ sal my vergun as ek hier op 'n heel besonder persoonlike vlak ook verwys na Artikel 81 van die Handelinge van die Sinode. Daar staan genotuleer:

"De zitting werd gesloten met het zingen van Ps. cxvi:10 en gebed door ouderling J.J. Reinecke".

Miskien het die eerbiedwaardige ouderling daardie Vrydagoggend met die keuse van die psalm probeer verwoord wat in die gemoed van die afgevaardigdes geleef het: "Wat kan ons die Heer vir al sy guns vergeld; wat kan ons hom bring uit dank van sy genade?" As deputaat was hy een van die 38 persone wat hier in 1869 te Potchefstroom medebesluit het tot die stigting van die nuwe inrigting. As mens was hy Josias Johannes Reinecke, vader van Carolus Johannes Reinecke, sy derde seun, die grootvader van my vader wat vanaand ook hier teenwoordig is.

Gedurende die geskiedenis van die inrigting was die behoud van die Christelik-historiese karakter daarvan altyd een van die sentrale dryfkragte vir die inrigting. By uitnemendheid geld vandag vir die PU vir CHO wat in die verslag van die $\mathrm{KUH}$ oor die partikulariteit van 'n universiteit gestel is: 
"Die universiteit is ook in sosiale instelling wat in 'n spesifieke maatskaplike en kulturele omgewing funksioneer. Die universiteit kom tot stand in, en word ondersteun deur 'n bepaalde gemeenskap met 'n eie taal, eie tradisies, gebruike en strewes, 'n eie waarde-oriëntasie, 'n eie geskiedenis en 'n eie sin van bestemming."

Die keuringsmodel wat die stigters van die inrigting gebruik het om hulle partikulariteit te beskerm, moes onafwendbaar met verloop van tyd verander. In 1921, toe die inrigting as die Potchefstroomse Universiteitskollege deel van die konstituerende kolleges van die Universiteit van Suid-Afrika geword het, moes die keuringsbeginsel vir toelating van sowel die studente as dosente verval. Wat die dosente betref, het die inrigting 'n onafgebroke stryd gevoer vir lewensbeskoulike keuring van die personeel, spesifiek deur vrystelling van klousule 25 van Wet No. 12 van 1916, die sogenaamde gewetensklousule. Met die aansoek tot selfstandigwording is hierdie stryd van die inrigting fel op die spits gedryf in die Volksraad van die Unie van Suid-Afrika. Die debat oor die aangeleentheid het gelei tot nie minder nie as 100 Hansard-bladsye van die derde sitting van die tiende parlement in 1950 - hoofsaaklik oor die versoek van die universiteit vir die behoud van sy karakter - 'n versoek wat na hierdie debat uiteindelik per stemming goedgekeur is. Die betekenis hiervan het prof. J. Chr. Coetzee op 19 Februarie 1954 tydens sy intreerede as Rektor van die Potchefstroomse Universiteit vir Christelike Hoër Onderwys soos volg verduidelik:

"Die Potchefstroomse Universiteit vir Christelike Hoër Onderwys is dus 'n belydende inrigting: wat sy personeel betref, geslote, maar wat sy studente betref ope. Ons mag dus met reg sê dat hierdie inrigting 'n openbare inrigting vir Christelike hoër onderwys is".

Die gemeenskap waaruit en warvoor die universiteit tot stand gekom het, het kultureel en kerklik verbreed, maar vorm nog steeds 'n belangrike snit van die Suid-Afrikaanse samelewing en die universiteit ervaar steeds dat studente vanuit daardie gemeenskap vanoor die lengte en breedte van die land na Potchefstroom vir hulle universiteitsopleiding kom. Vir daardie gemeenskap, en in verantwoordelikheid teenoor die roeping van die $\mathrm{PU}$ vir $\mathrm{CHO}$ sal die Christelik-historiese karakter daarom ook in die tyd wat kom onverswak gehandhaaf word. Weens die druk vir akademiese gehalte en veral die 
groeibeperkings wat die Staat die universiteite spesifiek vanaf 1988 ten laste gelè het, moet elke universiteit steeds strenger akademiese keuringsnorme vir die toelating van studente implementeer. Hierdie keuringsgronde, tesame met die taal en kulturele milieu van die universiteit het tot gevolg dat die voltydse residensiële studente op beide die Potchefstroomse en Vaaldriehoekse kampusse van die Universiteit sterk verteenwoordigend is van die kulturele gemeenskap wat die universiteit bedien, en sal die samestelling van daardie studentegemeenskappe waarskynlik ook in die toekoms oorwegend so bly.

Terselfdertyd is die toename in leerders wat vir na-skoolse opleiding kwalifiseer uit daardie deel van ons land se bevolking wat nie verteenwoordigend van ons tradisionele ondersteuningsgemeenskap is nie, ook ' $n$ realiteit. Die $\mathrm{PU}$ vir $\mathrm{CHO}$ mag nie afsydig teenoor hierdie werklikhede van die land en verwagtinge van daardie jeug staan nie. Op verskeie fronte is die universiteite reeds besig om antwoordgewend op hierdie verantwoordelikheid te reageer. Voornemende studente van enige taal- of bevolkingsgroep kan voltyds aan die universiteit studeer, mits aan die keuringsvereistes voldoen word, en studente van ander taal- en bevolkingsgroepe, sy dit dan op beperkte skaal, maak van daardic moontlikheid gebruik. Veel meer (inderdaad honderde) studente uit ander bevolkingsgroepe het in ' $n$ toenemende mate vir die afgelope aantal jare en tans ook gebruik gemaak van ander akademiese aanbiedings van die PU vir CHO.

Die belangrikste hiervan is die buitemuurse klasse wat op die Potchefstroomse sowel as die Vaaldriehoekse kampusse aangebied word. Ten einde op 'n nog omvattender vlak hier diensbaar te wees, mag dit in die toekoms vir die PU vir $\mathrm{CHO}$ nodig wees om op 'n geselekteerde basis ook van hierdie na-uurse programme binne sy gebied van jurisdiksie geografies verder te desentraliseer asook om dit in ' $n$ Engelstalige medium aan te bied ten einde meer studente met behulp van daardie program te bedien. Die ander akademiese aanbiedings wat in besondere bydrae tot die ander bevolkingsgroepe lewer, is die wat in assosiasie met ander instellings plaasvind. So is daar reeds in aantal verpleegkolleges, wat jaarliks aan groot getalle (hoofsaaklik) swart verpleegsters opleiding verskaf, by die universiteit geakkrediteer. 'n Verbeeldingryke ooreenkoms is met die Universiteit van Suid-Afrika, oud-patronaat van die $\mathrm{PU}$ vir $\mathrm{CHO}$, aangegaan vir opleiding in die lewenswetenskappe. Daardie universiteit finansier tans die salarisse van personeel op die dienssteat van die $\mathrm{PU}$ vir $\mathrm{CHO}$ en dra ook by tot die bedryfs. 
en kapitaalbenodigdhede vir die opleiding wat deur daardie personeel op die model van afstandsonderrig aan die UNISA-studente vanuit ons kampus aangebied word. Daardie studente wat oorwegend van ander taal- en bevolkingsgroepe is, kom gedurende die resestye na Potchefstroom en skakel ten volle by die plaaslike laboratoria-fasiliteite in en ontvang ook residensievergunning vir hulle verblyf. Uit 'n akademiese oogpunt is die na-uurse en afstandonderrigprogramme hoogs suksesvol soos ook uit die hoë slaagsyfer van die studente blyk. Hierdie sukses het die Universiteit gemotiveer om ook die universiteit VISTA te nader met die oog op saamsnoering van kragte en fasiliteite by die Vaaldriehoekkampus waruit besondere verdere bydraes gelewer sal kan word.

\subsection{Geestelike waardes}

Dit is nie alleen die kwantiteit studente wat gelewer word wat van belang is nie, maar veral die kwaliteit wat van deurslaggewende belang is. Dit gaan hier dus om die toerusting tot leierskap vir die studente van die PU vir CHO. Wat die akademie betref, is die handhawing van hoë standaarde so 'n noodsaaklike vereiste, dat dit eintlik nie eers genoem moet word nie. Deur die kragtige uitbouing van nagraadse opleiding en navorsing en hoëvlak navorsing deur die personeel kan die milieu versterk word vir die deeglike wetenskaplike vorming van die studente. Nie alleen wetenskaplike kennis nie, maar veral kennis oor die proses van wetenskapsvorming, met klem op die bestudering van die beginsels wat grondliggend aan die vakwetenskappe is, moet ingeskerp word. As een hoofdoelwit moet gestreef word na wetenskapsbeoefening van 'n hö̈ gehalte met die oog op hoëvlak beroepsvoorbereiding. Meer nog, die universiteit het ook ten taak om die wetenskap en sy grondslae deurtastend te deurgrond en in sy diepste betekenis te evalueer, soos prof. H.J.J. Bingle dit met sy intreerede as Rektor op 14 Februarie 1964 gestel het:

"Die wetenskaplike van alle tye moet die fenomene van die kosmos nie alleen intrinsiek navors en beoordeel nie, maar ook in hulle onderlinge verband en in die tydsgewrig waarin hy leef, ondat die bepaalde wêreldkonstellasie aan hierdie verskynsels steeds 'n besondere kleur gee, al sou dit die inherent-wesentlike daarvan nie radikaal verander nie; en ten slotte moet hy alles nog in hulle transendente verband plaas." 
As universiteit wat ook karaktervormend wil funksioneer, is dit juis die taak van die PU vir $\mathrm{CHO}$ om sy studente hierin toe te rus om deur kritiese denke tot die wese, grondslae en etick van die wetenskap en tegniek deur te dring, dit prinsipieel te beoordeel en van daaruit paraat te wees om rigtinggewend op sy vakkundige gebied te arbei. Slegs toegerus met so 'n mondering kan die afgestudeerde student werklik as leier in die gemeenskap gaan leef en werk. Die PU vir CHO het reeds veel op hierdie gebied van vakfilosofiese navorsing gedoen en word binne die korps van geesgenootlike inrigtings internasionaal as leier hiervan erken. Tans kom studente ook wèreldwyd na die PU vir CHO, veral vir nagraadse studie, juis vanweë hierdie vakfilosofiese begronding vanuit die Christelike lewens- en wèreldbeskouing. Meer formele interfakultêre strukturering, asook internasionale skakeling met geesgenootlike inrigtings en kollegas, staan daarom hoog op die agenda om hierdie taak van die universiteit op 'n nog hegter grondslag te plaas. Die lewensbeskoulike strominge van die huidige en toekomstige tydsgewrig mak die noodsaak van hierdie ontwikkeling buitengewoon aktueel vir die Christelike universiteit.

\subsection{Wetenskap en tegnologie}

Die derde omgewingsfaktor wat deurslaggewend vir die toekoms van Suid-Afrika sal wees, is die vlak waarop wetenskap en tegnologie op die duur beoefen sal word. Die jongste tendens wereldwyd is dat universiteite en industrieë in vennootskap begin om hierdie noodsaaklike element in belang van ' $n$ lewenskragtige land te eksploiteer. Die volgende aanhaling uit Industry and Higher Education stel dit so duidelik:

"This is a time of great challenges to the university world, not only in its struggle with finances, but in finding its true role in the modern society. It is clear, to even the most casual observers, that there is a profound change taking place in higher education institutes throughout the world in their attitudes towards cooperation with industry. Central to this entire movement is the issue of research. In contrast to the situation a decade or so ago, the results of basic research in the universities are often of immediate and vital importance to those in industry concerned with product development. Industries today must innovate to survive and they look more now to the intellectual expertise and laboratory facilities of the universities for new ideas. They realize 
that their technical staff need continual retraining and updating in their disciplines and here the universities have an important role to play with their continuing education programmes".

Op die Raadsvergadering van die PU vir CHO (November 1988) het hierdie belangrike nuwe ontwikkeling wat in die universiteitswese in die buiteland plaasvind, aan die orde gekom en het die Raad die visie gehad om te besluit dat die PU vir CHO ook in hierdie ontwikkeling moet deel. Daarmee bevestig die PU vir CHO die noodsaak van 'n vennootskap tussen universiteit en die industrie en die openbare sektor vir die gesamentlike verantwoordelikheid ten opsigte van die ontwikkeling van die wetenskap en tegnologie in belang van die toekoms van die land. Hierdie nuwe formalisering van in vennootskap tussen universiteit en industrie is nie 'n radikaal nuwe ontwikkeling vir die PU vir CHO nie, maar die logiese uitvloeisel van die rol wat die universiteit reeds in die verlede ten opsigte van gemeenskapsdiens vervul het. In sy intreerede gehou op 10 Februarie 1978 het prof. Tjaart van der Walt, vorige Rektor van die $\mathrm{PU}$ vir $\mathrm{CHO}$, ons universiteit onder andere as "'n akademiese diensgemeenskap met durf vir die toekoms" getipeer. Hy het dit só gestel:

"Hierdie gemeenskap is ingestel op diens. Geen universiteit is in doel op sigself nie. Elke universiteit is 'n diensorganisasie wat alleen bestaansreg het solank die diens wat hy lewer dit regverdig ... Dit is ook ' $n$ diens na buite, deur die studente wat die universiteit vir die maatskappy lewer, maar ook deur die navorsing van die universiteit".

Om die vennootskapsiol van die PU vir $\mathrm{CHO}$ uit te voer, het die Raad op senior vlak die pos van Bestuurder: Tegnologie en Ontwikkeling ingestel. Daarmee wil die universiteit bevestig dat hy op die toepaslike gebiede waar daar besondere deskundigheid bestaan, wil bydra tot die noodsaaklike proses van wetenskaplike en tegnologiese innovasie wat so noodsaaklik vir die toekoms van die land is. Hiermee reik die universiteit ' $n$ hand na die industriële en openbare sektor om só op die voorpunt te beweeg vir die gesamentlike verantwoordelikheid wat al hierdie partye dra. Met hierdie ontwikkeling word ook beoog om die finansiële bronne, toerusting en fasiliteite van die universiteit in aanvulling tot die bydrae vanaf die staat te verstewig, maar veral ook om die deskundigheid en relevansie van die navorsing by die universiteit te verdiep. Daar is vandag 'n sterk beweging om relevansie as verafrikanisering 
van die akademiese programme en navorsing van die universiteit te interpreteer. Inderdaad, in Afrika en gerig op Afrika behoort $n$ wesentlike blikrigting vir elke universiteit in Suid-Afrika te wees. Maar dan beslis relevant, alleenlik en juis onder die vaandel van die hoogste akademiese standaarde soos wat dit in die internasionale universitère gemeenskap geld. Slegs deskundigheid van die hoogste gehalte sal we:klik die toetssteen van relevansie en van die tyd kan deurstaan - ook in Afrika.

\section{SLOTOPMERKINGS}

Hooggeagte lede van die Raad van die PU vir CHO, met my benoeming as Rektor van die PU vir CHO het $u$ in groot verantwoordelikheid op my geplaas. Die erns hiervan is in sy diepte nèrens duideliker gestel as deur prof. Ferdinand Postma nie, toe hy in 1942, midde in die Tweede Werreldoorlog ten tye van die mondigwording van die Potchefstroomse Onderwyskollege vir Christelike Hoër Onderwys verklaar het:

"Tye is moeilik, miskien die moellikste wat nog ooit beleef is en die toekoms baie donker... Hoe moeiliker die stryd word, hoe meer tree te voorskyn die staalkragtige beginsels waardeur die lewe gedra word. Die beginsels van die PUK vir CHO is die lewensessensie van alle geestelike bestaan. Net so min as wat die beginsels ooit verbreek of uitgewis kan word, net so min kan nasies of inrigtings wat eerlik en opreg die beginsels handhaaf, in toepassing bring en uitleef, ooit ondergaan. Maar - en dit is 'n groot maar - dan moet die beginsels waaragtig bely en beleef word. So nie, dan kan wis en seker uitwissing verwag word. Swaar en groot is dus die verantwoordelikheid wat rus op die professore, dosente en studente van die PUK vir CHO. Die beginsels is vuur, hemelse vuur! Wie ligvaardig daarmee ongaan, sal verteer word en tot as verbrand, maar wie ootmoedig deur die Lig gelei word, sal voortgaan van krag tot krag".

Op hierdie fondament, geagte here van die Raad, kollegas, studente, familie en vriende, en in hierdie gees aanvaar ek die verantwoordelikheid wat die amp meebring. Net die beste van my kragte sal ek daarvoor gee. Maar ons weet onk en bely: dit is die Here wat roep en Hy is ook getrou. Hy gee ook die 
toerusting vir elke taak. Daarom loof ons Hom as individuele gelowiges maar ook as belydende universiteit. Soli Deo Gloria: aan God alleen die eer.

Ek dank u vir $\mathrm{u}$ aandag.

C.J. Reinecke

10 Februarie 1989 